\title{
Identification of a novel Getah virus by Virus-Discovery-CDNA random amplified polymorphic DNA (RAPD)
}

Tingsong $\mathrm{Hu}^{1+}$, Ying Zheng ${ }^{1+}$, Yan Zhang ${ }^{2 \dagger}$, Gangshan $\mathrm{Li}^{1}$, Wei Qiu ${ }^{1}$, Jing Yu${ }^{1}$, Qinghua Cui ${ }^{1}$, Yiyin Wang ${ }^{1}$, Chaoxiong Zhang ${ }^{1}$, Xiaofang Zhou', Ziliang Feng ${ }^{1}$, Weiguo Zhou' ${ }^{1}$, Quanshui Fan ${ }^{1 *}$ and Fuqiang Zhang ${ }^{1 *}$

\begin{abstract}
Background: The identification of new virus strains is important for the study of infectious disease, but current (or existing) molecular biology methods are limited since the target sequence must be known to design genome-specific PCR primers. Thus, we developed a new method for the discovery of unknown viruses based on the cDNA - random amplified polymorphic DNA (CDNA-RAPD) technique. Getah virus, belonging to the family Togaviridae in the genus Alphavirus, is a mosquito-borne enveloped RNA virus that was identified using the Virus-Discovery-cDNA RAPD (VIDISCR) method.

Results: A novel Getah virus was identified by VIDISCR from suckling mice exposed to mosquitoes (Aedes albopictus) collected in Yunnan Province, China. The non-structural protein gene, nsP3, the structural protein gene, the capsid protein gene, and the 3'-untranslated region (UTR) of the novel Getah virus isolate were cloned and sequenced. Nucleotide sequence identities of each gene were determined to be 97.1-99.3\%, 94.9-99.4\%, and 93.6-99.9\%, respectively, when compared with the genomes of 10 other representative strains of Getah virus.

Conclusions: The VIDISCR method was able to identify known virus isolates and a novel isolate of Getah virus from infected mice. Phylogenetic analysis indicated that the YN08 isolate was more closely related to the Hebei HB0234 strain than the YN0540 strain, and more genetically distinct from the MM2021 Malaysia primitive strain.
\end{abstract}

Keywords: Getah virus, Identification, Virus-Discovery, cDNA RAPD

\section{Background}

Viruses in the genus Alphavirus belong to the group IV Togaviridae family and include nearly 30 virus species [1]. Alphaviruses are able to infect humans and various vertebrates via arthropods, such as mosquitoes. The 11-12 kb Alphavirus genome is a single-stranded positive sense RNA flanked by a 5' terminal cap and 3' polyA tail, and composed of four non-structural proteins genes (nsP1 to nsP4) and five structural proteins gene (C (nucleocapsid), E3, E2, $6 \mathrm{~K}$, and E1 proteins) [2]. Getah virus (GETV) is a mosquito-borne enveloped RNA virus belonging to the Semliki Forest virus (SFV) complex in the genus Alphavirus [1]. To date, 10 strains of GETV

\footnotetext{
*Correspondence: fqs168@126.com; zfq1968@yahoo.com.cn

${ }^{\dagger}$ Equal contributors

${ }^{1}$ Centre for Disease Control and Prevention, Chengdu Military Region, Kunming 650032, China

Full list of author information is available at the end of the article
}

have been isolated in China: M1, HB0234, HB0215-3, YN0540, YN0542, SH05-6, SH05-15-17 and GS10-2 [3]. GETV has been shown to cause illnesses in humans and livestock animals and antibodies to GETV have been detected in many animal species worldwide [4-6].

The identification of novel virus species is important for the identification and characterization of disease. However, present research methods are mostly applicable for known viruses but few methods exist to characterize unknown viruses. Current molecular biological techniques for the identification of new virus species are troublesome since some viruses do not replicate in vitro but some may cause a cytopathic effect. Furthermore, specific techniques that require sequence identification are not applicable. To overcome these limitations, we developed a new method for virus discovery: VirusDiscovery-cDNA RAPD (VIDISCR), based on the

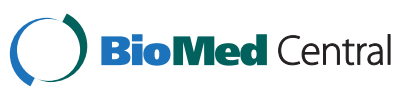


cDNA-random amplified polymorphic DNA technique (cDNA-RAPD) [7-11]. VIDISCR includes two key steps. First, the virus genome nucleic acid must be isolated without cellular RNA and DNA contamination. Second the RAPD analysis using the virus genome cDNA or DNA. Using this method, we tested known viruses (SV40 and SV5) and identified a new Getah virus YN08 strain. Virus nsP3, capsid protein genes, and 3'-UTR sequences were cloned, sequenced, and compared. The phylogenetic analysis indicated that the virus YN08 isolate is more closely related to Hebei HB0234 strain than the YN0540 strain, and genetically distant to the MM2021 Malaysia primitive strain.

\section{Results}

\section{Virus isolation}

Acute encephalitis syndrome (AES) was observed in suckling mouse with growth retardation, panting, abdominal breathing, and arthritis (data not shown). Negative-staining electron microscopy (EM) of the supernatant from infected suckling mouse brain (named YN08) revealed virus-like particles (Figure 1). These particles were spherical in shape, with an envelope, and approximately $50-70 \mathrm{~nm}$ in diameter, consistent in size and morphology with that of Togaviruses or Flaviviruses.

\section{Virus discovery using VIDISCR}

The VIDISCR method was developed based on the cDNA-RAPD technique $[8,9,11]$. VIDISCR begins with a treatment to selectively enrich for viral nucleic acid. To remove the interferences from the cell genomes DNA



and cellular RNA, a centrifugation step is used to remove residual cells and mitochondria (Figure 2A) and A DNase (and RNase) treatment is also used to remove interfering chromosomal and mitochondrial DNA (and cellular RNA) from degraded cells, where the viral nucleic acid is protected within the virus particle. The viral nucleic acids of SV40 and SV5 were detected by the VIDISCR method (Figure 2B) from cell culture, demonstrating its capacity to identify both DNA and RNA viruses (Figure $2 \mathrm{~B}$ and Table 1 ).

The supernatant of the suckling mouse brain tissue infected with YN08 was analyzed by VIDISCR. The supernatant of uninfected suckling mouse brain tissue was used as a negative control. Unique amplified DNA fragments were present in the test sample but not in the control where the 11 reactions gave prominent DNA fragments in 20 VIDISCR selective PCR reactions $(11 / 20$ selective PCR; Figure $2 C$ \& D, Table 1). The 21 VIDISCR fragments were cloned and sequenced from the 11 selective PCR assays. Thirteen of 21 fragments showed sequence similarity to members of the Togaviridae family with 98\% identity to GETV using the basic local alignment search tool (BLAST).

\section{PCR amplification, sequence analysis, and phylogenetic comparisons}

Using VIDISCR, the non-structural protein gene nsP3, the structural protein gene capsid protein gene and 3'-UTR sequences of the YN08 isolate were amplified, cloned, and sequenced. Other GETVs non-structural protein genes nsP3, capsid protein genes and 3'-UTR sequences obtained from databases were compared, including those from MM2021 (Malaysia), MAG (Russia), ALPV_M1, (China) GETV_M1 (China), MPR (Mongolia), S_KOREA (South Korea), HB0234 (China Hebei, China), YN0540 (Yunan, China), and SAGV (Sagiyama virus from Japan). The YN08 isolate non-structural protein gene nsP3, the structural protein gene (capsid protein gene), and 3'-UTR sequence identity were 97.1-99.3\%, 94.9-99.4\%, and 93.6-99.9\%, respectively, by alignment with 10 strains of Getah virus found worldwide. Analysis of all sequences (nsP3, capsid protein gene, and 3'-UTR) included in this study showed the highest nucleotide sequence identity between YN08 and GETV HB0234 strains.

The YN08 isolate nsP3 nucleotide sequences identity ranged from 98.00 to $99.31 \%$, while amino acid sequence identity ranged from 98.89 to $99.44 \%$ (Table 2) between YN08 isolates and other Chinese isolates (GETV_M1 [12], ALPV_M1 HB0234, and YN0540). The capsid protein gene nucleotide sequence identity ranged from 97.56 to $99.31 \%$, while amino acid sequence identity ranged from 98.27 to $99.66 \%$ (Table 3) between YN08 isolates and other Chinese isolates (GETV_M1 [12], ALPV_M1 HB0234 and YN0540). 


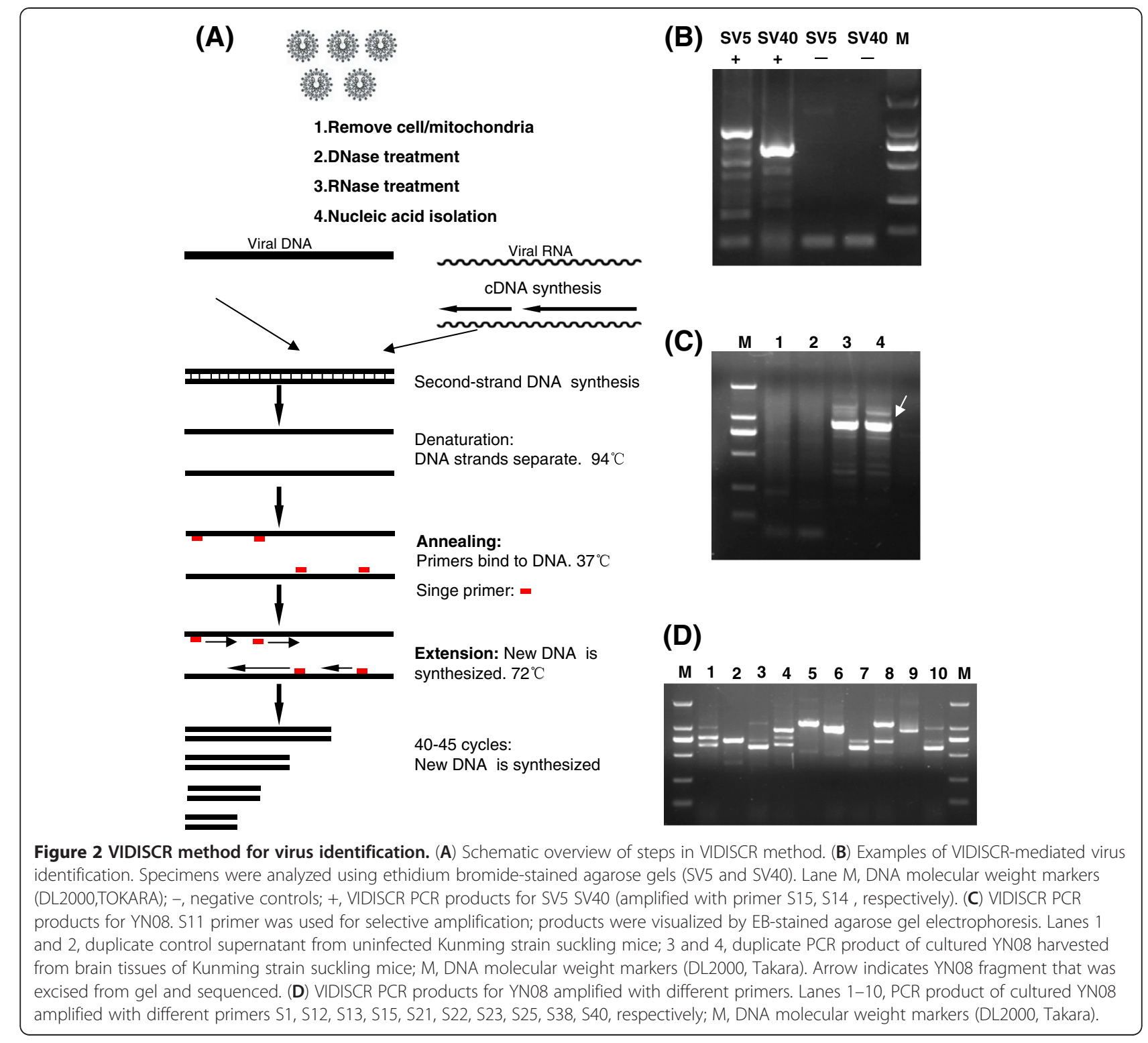

Alphaviruses possess a highly conserved 3' sequence element (3' CSE; approximately $19 \mathrm{nt}$ long) that immediately precedes the poly(A) tail [2]. Both the poly(A) tail and the 3'CSE are required for virus replication and, more specifically, for efficient minus-strand RNA synthesis [13-17]. The terminal 19 nt conserved sequence was identical in all GETV isolates, including the M1 isolate that was previously reported to have lost this conserved sequence $[18,19]$.

Alignment with the other nine strains of Getah virus indicated that the 3'-UTR sequence homology between YN08 isolate and other Chinese isolates (GETV_M1, ALPV_M1, HB0234 and YN0540) ranged from 99.65 to 99.77\% (Table 4). Analysis of all 3'-UTR sequences included in this study showed the highest nucleotide sequence identity between the YN08 isolate and MPR
GETV (99.89\%) and the nucleotide sequence identity was lowest between the YN08 isolate and the South Korean isolate (93.61\%).

\section{Phylogenetic analysis}

To better understand the genetic relationship of YN08 to other strains of Getah virus in the world (including Chinese isolates ALPV_M1, GETV_M1, HB0234, and YN0540), the previously published genetic sequences of GETV and other alphavirus capsid protein genes and 3'UTR sequences obtained from GenBank were used to construct phylogenetic trees. The phylogenetic analyses clearly showed that YN08 is more closely related to the Hebei HB0234 strain than the YN0540 strain, and more distantly related to the MM2021 Malaysia primitive strain (Figure 3). 
Table 1 RAPD Primers used for VIDISCR and the result of Virus discovery by the VIDISCR method

\begin{tabular}{ccccc}
\hline Primer & Sequence (5'-3') & SV5 & SV40 & YN08 \\
\hline S1 & GTTCGCTCC & $\mathrm{N}$ & $\mathrm{N}^{*}$ & $2 / 3$ \\
S2 & TGATCCCTGG & $\mathrm{N}$ & $1 / 3^{*}$ & $\mathrm{~N}$ \\
S3 & CATCCCCCTG & $2 / 2$ & $\mathrm{~N}$ & $\mathrm{~N}$ \\
S4 & GGACTGGAGT & $1 / 3$ & $\mathrm{~N}$ & $\mathrm{~N}$ \\
S5 & TGCGCCCTC & $\mathrm{N}$ & $1 / 2$ & $\mathrm{~N}$ \\
S11 & GTAGACCCGT & $1 / 3$ & $\mathrm{~N}$ & $1 / 1$ \\
S12 & CCTTGACGCA & $2 / 3$ & $1 / 1$ & $1 / 2$ \\
S13 & TTCCCCCGCT & $\mathrm{N}$ & $\mathrm{N}$ & $1 / 2$ \\
S14 & TCCGCTCTGG & $1 / 1$ & $1 / 2$ & $\mathrm{~N}$ \\
S15 & GGAGGGTGT & $2 / 3$ & $\mathrm{~N}$ & $2 / 2$ \\
S21 & CAGGCCCTC & $\mathrm{N}$ & $\mathrm{N}$ & $2 / 2$ \\
S22 & TGCCGAGCTG & $\mathrm{N}$ & $\mathrm{N}$ & $1 / 2$ \\
S23 & AGTCAGCCAC & $1 / 3$ & $\mathrm{~N}$ & $1 / 2$ \\
S24 & AATCGGGCTG & $\mathrm{N}$ & $\mathrm{N}$ & $\mathrm{N}$ \\
S25 & AGGGGTCTTG & $\mathrm{N}$ & $0 / 2$ & $1 / 2$ \\
S36 & AGCCAGCGAA & $2 / 4$ & $\mathrm{~N}$ & $\mathrm{~N}$ \\
S37 & GACCGCTTG & $1 / 1$ & $\mathrm{~N}$ & $\mathrm{~N}$ \\
S38 & AGGTGACCGT & $\mathrm{N}$ & $\mathrm{N}$ & $0 / 1$ \\
S39 & CAAACGTCGG & $\mathrm{N}$ & $1 / 2$ & $\mathrm{~N}$ \\
S40 & GTGGGATCC & $\mathrm{N}$ & $\mathrm{N}$ & $1 / 2$ \\
\hline
\end{tabular}

*Note: "N" denote The unique and prominent DNA fragments were not present in the test sample ; the denominator was the number of The unique and prominent DNA fragments by cloned and the numerator was the number of the virus DNA fragments in the test sample.

\section{Discussion}

Alphaviruses are mosquito-borne RNA viruses that cause devastating or debilitating diseases in both humans and livestock. SAGV and GETV are two members of the Alphavirus genus of the family Togaviridae. GETV is widely distributed in southeast Asia and northern Australia along the Pacific Ocean [20-24]. GETV has been isolated from various mosquito species of the genera Culex, Aedes, and Armigeres [18]. It is conceivable that GETV may use mammals as primary hosts in its enzootic cycle, and through these biting vectors, the virus may be transmitted to various animal species, including pigs, chickens, humans, and other mammals, on rare occasion, the virus may jump the species barrier and infect a human or other animal [25]. Although the virus has not been linked to illness in humans, many studies have suggested that the virus is a latent pathogen of humans causing a fever of unknown origin. GETV could cause illnesses in humans and livestock animals and, indeed, antibodies to GETV have been detected in many species of animals around the world [4-6].

Analysis of all sequences included in this study showed that the nsP3 non-structural protein gene and the capsid protein gene nucleotide sequence identity between YN08 isolates and other Chinese isolates (GETV_M1 [12], ALPV_M1, HB0234 and YN0540) ranged from 98.0 to $99.31 \%$ and 97.56 to $99.31 \%$, respectively. Multiple alignments showed that the S_Korea isolate does not possess the 92 nt sequence from 11341-11433 in the virus genome and there was a low level of identity (92.19-93.75\%) between S_Korea and other GETV strain at the 3'-UTR sequences. Despite possessing 3'-UTR sequences of different lengths, GETV isolates contain various numbers of an identical sequence element that could have originated from a large ancestral 3'-UTR [26,27].

Phylogenetic trees constructed using viruses sequence data are the best indication of the evolutionary relationships between viruses and genetic changes associated with antigenic drift. To provide further insight into the evolutionary relationship of YN08 and other alphaviruses, phylogenic analysis was performed based on the capsid protein gene and the 3'-UTR sequence of YN08 and other 9 alphaviruses. These analyses showed that YN08 is a member of the GETV and was most closely related to HB0234 and S_Korea and then with YN0540 and GETV_LEIV_17741_MPR to form a distinguishable

Table 2 Homology comparison of nucleotide (below the diagonal) and amino acid sequences (above the diagonal) of non-structural protein gene nsP3 of YN08 isolates Getah virus with other Alphavirus isolates

\begin{tabular}{|c|c|c|c|c|c|c|c|c|c|}
\hline & 1 & 2 & 3 & 4 & 5 & 6 & 7 & 8 & 9 \\
\hline 1. AlpV_M1 & & $99.07 \%$ & $98.89 \%$ & $98.89 \%$ & $99.07 \%$ & $100 \%$ & $98.89 \%$ & $98.70 \%$ & $99.07 \%$ \\
\hline 2. GETV_S_Korea & $98.4 \%$ & & $99.63 \%$ & $99.07 \%$ & $99.63 \%$ & $99.07 \%$ & $99.82 \%$ & $99.44 \%$ & $98.89 \%$ \\
\hline 3. GETV_HB0234 & $98.1 \%$ & $99.4 \%$ & & $98.89 \%$ & $99.26 \%$ & $98.89 \%$ & $99.44 \%$ & $99.44 \%$ & $98.70 \%$ \\
\hline 4. GETV_LEIV_16275_MAG & $97.9 \%$ & $97.4 \%$ & $97.2 \%$ & & $99.07 \%$ & $98.89 \%$ & $98.89 \%$ & $98.70 \%$ & $99.07 \%$ \\
\hline 5. GETV_LEIV_17741_MPR & $98.6 \%$ & $98.8 \%$ & $98.5 \%$ & $97.9 \%$ & & $99.07 \%$ & $99.44 \%$ & $99.07 \%$ & $98.89 \%$ \\
\hline 6. GETV_M1 & $99.9 \%$ & $98.5 \%$ & $98.2 \%$ & $98.0 \%$ & $98.7 \%$ & & $98.89 \%$ & $98.70 \%$ & $99.07 \%$ \\
\hline 7. GETV_YN08 & $98.0 \%$ & $99.3 \%$ & $99.3 \%$ & $97.1 \%$ & $98.3 \%$ & $98.1 \%$ & & $99.26 \%$ & $98.70 \%$ \\
\hline 8. GETV_YN0540 & $98.1 \%$ & $99.4 \%$ & $99.1 \%$ & $97.2 \%$ & $98.5 \%$ & $98.2 \%$ & $99.0 \%$ & & $98.51 \%$ \\
\hline 9. SAGV & $98.1 \%$ & $97.5 \%$ & $97.2 \%$ & $98.5 \%$ & $97.9 \%$ & $98.2 \%$ & $97.1 \%$ & $97.2 \%$ & \\
\hline
\end{tabular}


Table 3 Homology comparison of nucleotide and amino acid sequences of Capsid gene of YN08 isolates Getah virus with other Alphavirus isolates ${ }^{\text {a }}$

\begin{tabular}{|c|c|c|c|c|c|c|c|c|c|c|}
\hline & 1 & 2 & 3 & 4 & 5 & 6 & 7 & 8 & 9 & 10 \\
\hline 1. ALPV_M1 & & $99.66 \%$ & $99.66 \%$ & $99.66 \%$ & $98.97 \%$ & $97.57 \%$ & $99.66 \%$ & $99.31 \%$ & $99.66 \%$ & $99.31 \%$ \\
\hline 2. GETV_HBO234 & $98.50 \%$ & & $99.31 \%$ & $100 \%$ & $98.62 \%$ & $97.22 \%$ & $100 \%$ & $99.66 \%$ & $100 \%$ & $98.97 \%$ \\
\hline 3. GETV_LEIV_16275_Mag & $98.85 \%$ & $97.79 \%$ & & $99.31 \%$ & $98.62 \%$ & $97.22 \%$ & $99.31 \%$ & $98.97 \%$ & $99.31 \%$ & $98.97 \%$ \\
\hline 4. GETV_LEIV_17741_MPR & $99.20 \%$ & $98.85 \%$ & $98.27 \%$ & & $98.62 \%$ & $97.22 \%$ & $100 \%$ & $99.66 \%$ & $100 \%$ & $98.97 \%$ \\
\hline 5. GETV_M1 & $99.67 \%$ & $98.15 \%$ & $98.50 \%$ & $98.85 \%$ & & $96.51 \%$ & $98.62 \%$ & $98.27 \%$ & $98.62 \%$ & $98.27 \%$ \\
\hline 6. GETV_MM2021 & $96.25 \%$ & $95.14 \%$ & $95.90 \%$ & $95.64 \%$ & $95.88 \%$ & & $97.22 \%$ & $96.87 \%$ & $97.22 \%$ & $97.57 \%$ \\
\hline 7. GETV_S_Korea & $98.62 \%$ & $99.66 \%$ & $97.91 \%$ & $98.97 \%$ & $98.27 \%$ & $95.27 \%$ & & $99.66 \%$ & $100 \%$ & $98.97 \%$ \\
\hline 8. GETV_YN08 & $98.27 \%$ & $99.31 \%$ & $97.56 \%$ & $98.62 \%$ & $97.91 \%$ & $94.89 \%$ & $99.43 \%$ & & $99.66 \%$ & $98.62 \%$ \\
\hline 9. GETV_YN0540 & $98.50 \%$ & $99.32 \%$ & $97.80 \%$ & $98.86 \%$ & $98.15 \%$ & $95.15 \%$ & $99.43 \%$ & $99.08 \%$ & & $98.97 \%$ \\
\hline 10.SAGV & $98.03 \%$ & $97.2 \%$ & $98.04 \%$ & $97.68 \%$ & $97.68 \%$ & $96.50 \%$ & $97.32 \%$ & $96.96 \%$ & $97.44 \%$ & \\
\hline
\end{tabular}

Note: ${ }^{a}$ The lower left part represents the homologous rate of nucleotide sequence of viral Capsid gene The upper right part represents the homologous rate of amino acid sequence of viral Capsid gene.

branch based on nsP3 and capsid protein genes. Thus, the phylogenetic analysis clearly showed that YN08 is more closely related to Hebei HB0234 strain than YN0540 strain and more genetically distant to the MM2021 Malaysia primitive strain.

Present methods rely on prior genetic knowledge but are not effective for the identification of unknown viruses. Thus, we developed the simple VIDISCR method based on the cDNA-RAPD technique $[8,9]$. The RAPD technique is a type of PCR but random segments of DNA are amplified. Unlike traditional PCR analysis, RAPD does not require any specific knowledge of the DNA sequence of the target organism by the use of 10mer primers for the amplification of DNA. However, the resolving power of the VIDISCR method is prone to interference from DNA or RNA from the lysed host tissues and cells (or bacteria). Since VIDISCR relies on a large, intact DNA template sequence, it has some limitations in the use of degraded DNA samples. Therefore, the intact DNA template sequence of virus genomes required and chromosomal DNA, mitochondrial DNA, and cellular RNA must be removed from the preparation to perform VIDISCR. In the current study, approximately $50 \%$ of PCR assays amplified DNA fragments in 20 VIDISCR selective PCR reactions (11/20; Table 1) and 13 of 21 fragments showed sequence similarity to virus genes. Therefore, VIDISCR is a suitable method for the identification of unknown viruses.

The current study indicated that the VIDISCR is an efficient procedure for the identification of known and unknown viruses with the removal of contaminating cellular nucleic acids, optimized nucleic acid amplification, large-scale sequencing, and bioinformatics. The VIDISCR technology is general, non-selective, and rapid, that does not require prior knowledge of the target sequence. This technique could be adapted to include a set of universal primers for virus genomic analysis in a wide variety of species. VIDISCR can identify a range of known and unknown pathogens that can be applicable to clinical samples including tissues or culture

Table 4 Percent Identity (below the diagonal) and Divergence (above the diagonal) matrix of 3' UTR sequence of different Alphavirus isolates

\begin{tabular}{|c|c|c|c|c|c|c|c|c|c|c|}
\hline & 1 & 2 & 3 & 4 & 5 & 6 & 7 & 8 & 9 & 10 \\
\hline 1. ALPV_M1 & & 0.0035 & 0.0046 & 0.0023 & 0.0011 & 0.0118 & 0.0626 & 0.0035 & 0.0035 & 0.0011 \\
\hline 2. GETV_HBO234 & $99.65 \%$ & & 0.0082 & 0.0012 & 0.0023 & 0.0155 & 0.0640 & 0.0023 & 0.0023 & 0.0046 \\
\hline 3. GETV_LEIV_16275_Mag & $99.54 \%$ & $99.18 \%$ & & 0.0070 & 0.0058 & 0.0142 & 0.0656 & 0.0082 & 0.0082 & 0.0058 \\
\hline 4. GETV_LEIV_17741_MPR & $99.77 \%$ & $99.88 \%$ & $99.30 \%$ & & 0.0012 & 0.0143 & 0.0625 & 0.0011 & 0.0012 & 0.0035 \\
\hline 5. GETV_M1 & $99.89 \%$ & $99.77 \%$ & $99.42 \%$ & $99.88 \%$ & & 0.0130 & 0.0641 & 0.0023 & 0.0023 & 0.0023 \\
\hline 6. GETV_MM2021 & $98.82 \%$ & $98.45 \%$ & $98.58 \%$ & $98.57 \%$ & $98.70 \%$ & & 0.0781 & 0.0155 & 0.0155 & 0.0130 \\
\hline 7. GETV_S_Korea & $93.74 \%$ & $93.60 \%$ & $93.44 \%$ & $93.75 \%$ & $93.59 \%$ & $92.19 \%$ & & 0.0639 & 0.0640 & 0.0626 \\
\hline 8. GETV_YN08 & $99.65 \%$ & $99.77 \%$ & $99.18 \%$ & $99.89 \%$ & $99.77 \%$ & $98.45 \%$ & $93.61 \%$ & & 0.0023 & 0.0046 \\
\hline 9. GETV_YN0540 & $99.65 \%$ & $99.77 \%$ & $99.18 \%$ & $99.88 \%$ & $99.77 \%$ & $98.45 \%$ & $93.60 \%$ & $99.77 \%$ & & 0.0046 \\
\hline 10.SAGV(DNA) & $99.89 \%$ & $99.54 \%$ & $99.42 \%$ & $99.65 \%$ & $99.77 \%$ & $98.70 \%$ & 93.74 & $99.54 \%$ & $99.54 \%$ & \\
\hline
\end{tabular}




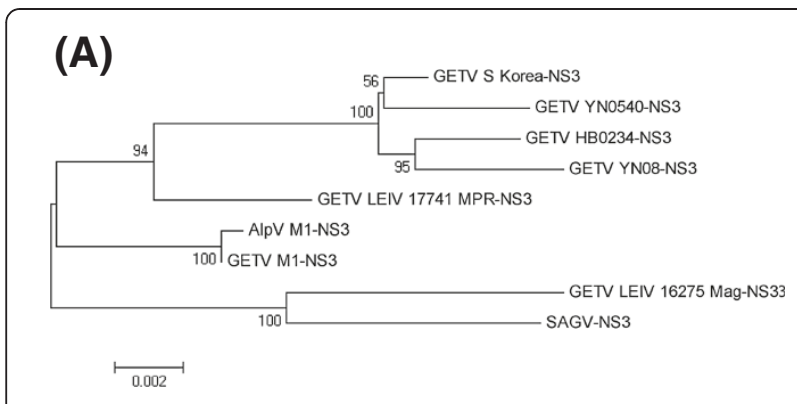

(B)

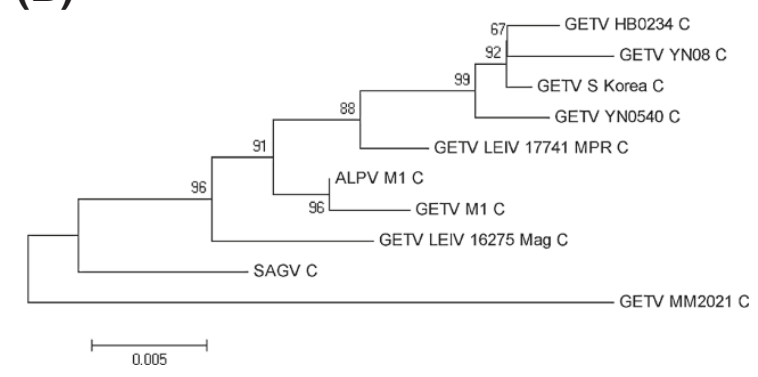

(C)

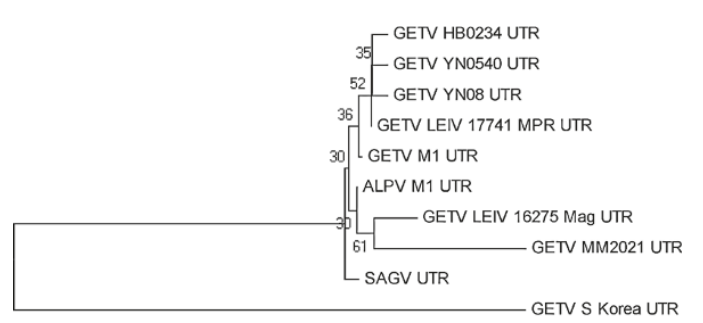

$\stackrel{501}{0.002}$

Figure 3 Phylogenetic relationship betweenYN08 isolates of GETV and other alphaviruses based on the non-structural protein gene nsP3, capsid protein and 3' UTR area sequences. The neighbor joining tree was constructed using the MEGA with bootstrapping. (A) Phylogenetic analysis of RT-PCR sequences of the non-structural protein gene nsP3 from YN08 isolates of GETV and other alphaviruses. (B) Phylogenetic tree constructed using the nucleotide sequences of the capsid gene of YN08 isolates of GETV and other alphaviruses. (C) Phylogenetic tree constructed using the nucleotide sequences of 3'-UTR area sequences of GETV isolates.

supernatants. Therefore, it is well suited for the rapid identification of an unknown or unexpected virus involved in a disease outbreak.

\section{Conclusions}

The present study described the isolation and identification of a new Getah virus YN08 with the VIDISCR method. Phylogenetic analysis indicated that the virus YN08 isolate was more closely related to Hebei HB0234 strain than YN0540 strain, and the virus was distantly related to the MM2021 Malaysia primitive strain. This study provided a VIDISCR method based on the cDNA-
RAPD technique that is well suited for rapid identification of known and unknown or unexpected viruses involved in a disease outbreak.

\section{Methods}

Mosquito collection, treatment, and virus isolation

Mosquitoes were collected from villages where livestock were bred in Yunnan province in 2008. Collection locations were within $10 \mathrm{~m}$ of henhouses, hog pens, and sheep pens. Collected mosquitoes were frozen for $30 \mathrm{~min}$ at $-20^{\circ} \mathrm{C}$ and then placed on an ice plate to determine mosquito species and to exclude blood-fed or male mosquitoes. Fifty to 100 mosquitoes were sorted into a collection tube and stored in liquid nitrogen. Pooled mosquitoes were added to $2 \mathrm{~mL}$ minimal essential medium (MEM, HyClone Laboratories, Inc. 925 West 1800 South Logan, Utah 84321) supplemented with $2 \mathrm{mM}$ glutamine, $0.12 \% \mathrm{NaHCO}_{3}, 100 \mathrm{U} / \mathrm{mL}$ penicillin, and $100 \mathrm{U} / \mathrm{mL}$ streptomycin, followed by grinding in a pre-cooled sterile plastic grinding tube. The ground samples were centrifuged at $13800 \times \mathrm{g}$ in a microcentrifuge for $20 \mathrm{~min}$ at $4^{\circ} \mathrm{C}$. Virus isolation was attempted in suckling mouse brain by injecting $20 \mu \mathrm{L}$ of clarified supernatant in the capsule of brain of 2-3 day old Kunming mice. The use of animals complied with the guidelines of the Experimental Animal Ethics Committees of the Centre for Disease Control and Prevention, Chengdu Military Region.

\section{VIDISCR}

Virus controls, including SV40 and SV5, were cultured on Vero E6 cells. Culture supernatants of SV40 and SV5 viruses were analyzed by VIDISCR to assess the general applicability of the technique. The unknown (YN08) virus was cultured in the capsule of brain of 2-3 day old Kunming suckling mice. Pooled brain tissues containing virus were added to $2 \mathrm{~mL}$ MEM, followed by homogenization in a pre-cooled sterile plastic grinding tube. To remove residual cells and mitochondria, $110 \mu \mathrm{L}$ brain homogenate supernatant was centrifuges for $10 \mathrm{~min}$ at maximum speed $(17000 \times \mathrm{g})$ in a microcentrifuge at $4^{\circ} \mathrm{C}$. To remove chromosomal DNA and mitochondrial DNA from the lysed cells, $100 \mu \mathrm{L}$ of supernatant was transferred to a fresh tube and treated with DNase I for $45 \mathrm{~min}$ at $37^{\circ} \mathrm{C}$ (Takara) $[7,8]$. To remove host RNA from the preparation, the supernatant was treated with RNase A (Takara) for 5 min at $37^{\circ} \mathrm{C}$. Nucleic acids were extracted using the AxyPrep Body Fluid Viral DNA/RNA Miniprep Kit (Axygen, Inc.) [28]. The ribonuclease inhibitor is required to obtain the intact RNA sequence of virus genomes.

A reverse transcription reaction was performed with random hexamer primers (Takara) and Moloney murine leukemia virus reverse transcriptase (MMLV-RT; Invitrogen). Second-strand DNA synthesis was carried out 
using Sequenase II (Takara) without further addition of primers. A phenol-chloroform extraction was followed by ethanol precipitation. The cDNA-RAPD assay was performed as previously described [9-11], with some modifications. The PCR program commonly used for RAPD analysis with random 10-mer primers (Table 1) included a 30 -s template denaturing step at $94^{\circ} \mathrm{C}$, a 30 -s primer annealing step at $37^{\circ} \mathrm{C}$ and a 1-min primer extension step at $72^{\circ} \mathrm{C}$. RAPD primers were purchased from Sangon Biotech (Shanghai, China) and consisted of 2160 primers named from S1 to S2160 and for the current assay, 20 primers were chosen from the S1 to S40 subset. Thermocycling typically consisted of 45 cycles of these three steps to obtain a RAPD pattern. The PCR products were analyzed on ethidium bromide (EB)stained 2\% agarose gels and the amplified fragments of interest were cloned and sequenced using BigDye terminator reagents. Electrophoresis and data collection were performed using an ABI 377 instrument (ABI). DNA molecular weight markers were obtained from Takara.

\section{Identification of virus by electron microscopy}

GETV was observed by EM. Preparation of the sample from a $1 / 10$ volume of the brain extract from suckling mice included extraction with chloroform and incubation of the mixture for $30 \mathrm{~min}$ at $4^{\circ} \mathrm{C}$. The extract was then centrifuged at $13800 \times \mathrm{g}$ for $30 \mathrm{~min}$. The precipitate was resuspended in $5 \mathrm{mM}$ phosphate buffered saline (PBS; pH 7.2) and negatively stained with $2 \%$ phosphotungstic acid. Specimens were examined using a transmission electron microscope (Hitachi-8100, Japan) at $80 \mathrm{kV}$.

\section{PCR amplification and sequencing}

The Getah virus nsP3 non-structural protein gene, the structural protein gene capsid gene and 3'-UTR primer sequences used were as follows [29]: nsP3 gene sense primer NS3-S: 5'-ATG CCT GCA ACG GAT TGC-3', antisense primer NS3-R: 5'-CGG GCC AGT GTC AGA CG-3'; capsid gene sense primer GETC1: 5'-CAG GAT TAC ACT ACA TCT AAA G-3, antisense primer GETC2: 5'-ACG TTG GCT AAG ACG CAC ATC-3'; 3'-UTR sense primer GETU1: 5'-CGG CAA T GA CAT GGG TGC AGC-3' antisense primer GETU2: 5'-CTG TCA GCG AAT TCG GTA CTT TTT TTT TTT TTT TTT TG-3'. PCR conditions were $94^{\circ} \mathrm{C}$ for $3 \mathrm{~min}$, followed by 40 cycles of DNA amplification $\left(45 \mathrm{~s}\right.$ at $94^{\circ} \mathrm{C}$, $1 \mathrm{~min}$ at $61^{\circ} \mathrm{C}$, and $1 \mathrm{~min} 30 \mathrm{~s}$ at $72^{\circ} \mathrm{C}$ ) and $8 \mathrm{~min}$ incubation at $72^{\circ} \mathrm{C}$. PCR products were analyzed on $1.2 \%(\mathrm{w} / \mathrm{v})$ agarose gels by electrophoresis at a constant voltage $(2 \mathrm{~V} / \mathrm{cm})$. The non-structural protein gene nsP3, the capsid proteins genes and 3'-UTR sequences were cloned and sequenced.

\section{Sequence analysis and phylogenetic comparisons}

Sequence data were analyzed using computer programs such as DNAMAN and DNASTAR. Phylogenetic analyses were performed by the neighbor-joining method using MEGA (version 5.05; http://www.megasoftware.net/). Previously published GETV sequences used in this study include sequences YN08 isolates MM2021 (from Malaysia, GenBank:AF339484), MAG (from Russia, EF631998), ALPV_M1 x(from China, EF011023), GETV_M1 (from China Hainan, EU015061), MPR (MPR from Mongolia, EF631999), S_KOREA (from South Korea, AY702913), HB0234(from China Hebei, EU015062), YN0540 (from China Yunan, EU015063), and SAGV (Sagiyama virus from Japan, AB032553).

\section{Competing interests}

The authors declare that they have no competing interests.

\section{Authors' contributions}

Tingsong Hu, Ying Zheng and Yan Zhang participated in the design and conducted the majority of the experiments in the study and drafted the manuscript. Gangshan Li, Wei Qiu and Jing Yu carried out the molecular genetic studies, participated in the sequence alignment. Qinghua Cui,Yiyin Wang, Caoxiong Zhang and Xiaofang Zhou contributed to the interpretation of the findings and revised the manuscript. Ziliang Feng and Weiguo Zhou performed the analyses of transmission electron microscope. Quanshui Fan and Fuqiang Zhang participated in the design of the study and performed the statistical analysis. All authors read and approved the final manuscript.

\section{Acknowledgments}

We thank Ms. Ming Qing for her administrative assistance. This work was financially sponsored by the key program (no. U1036601) and the youth fund program(no. 81101618) from the National Natural Science Foundation of China.

\section{Author details}

${ }^{1}$ Centre for Disease Control and Prevention, Chengdu Military Region, Kunming 650032, China. ${ }^{2}$ Department of Biochemistry and Molecular Biology, Fudan University Shanghai Medical College, Shanghai 200030, China.

Received: 16 April 2012 Accepted: 18 December 2012 Published: 27 December 2012

\section{References}

1. Weaver SC: Host range, amplification and arboviral disease emergence. Arch Virol Suppl 2005, 19:33-44.

2. Pfeffer M, Kinney RM, Kaaden OR: The alphavirus 3'-nontranslated region: size heterogeneity and arrangement of repeated sequence elements. Virology 1998, 240(1):100-108.

3. Liu H, Gao X, Liang G: Newly recognized mosquito-associated viruses in mainland China, in the last two decades. Virol J 2011, 8(1):68.

4. Kanamitsu M, Taniguchi K, Urasawa S, Ogata T, Wada Y, Wada Y, Saroso JS: Geographic distribution of arbovirus antibodies in indigenous human populations in the Indo-Australian archipelago. Am J Trop Med Hyg 1979, 28(2):351-363.

5. Li XD, Qiu FX, Yang H, Rao YN, Calisher CH: Isolation of Getah virus from mosquitos collected on Hainan Island, China, and results of a serosurvey. Southeast Asian J Trop Med Public Health 1992, 23(4):730-734.

6. Marchette NJ, Rudnick A, Garcia R: Alphaviruses in Peninsular Malaysia: II. Serological evidence of human infection. Southeast Asian J Trop Med Public Health 1980, 11(1):14-23.

7. Allander T, Tammi MT, Eriksson M, Bjerkner A, Tiveljung-Lindell A, Andersson $B$ : Cloning of a human parvovirus by molecular screening of respiratory tract samples. Proc Natl Acad Sci U S A 2005, 102(36):12891-12896.

8. van der Hoek L, Pyrc K, Jebbink MF, Vermeulen-Oost W, Berkhout RJ, Wolthers KC, Wertheim-van Dillen PM, Kaandorp J, Spaargaren J, Berkhout B: Identification of a new human coronavirus. Nat Med 2004, 10(4):368-373. 
9. Williams JG, Kubelik AR, Livak KJ, Rafalski JA, Tingey SV: DNA polymorphisms amplified by arbitrary primers are useful as genetic markers. Nucleic Acids Res 1990, 18(22):6531-6535.

10. Yoshida KT, Naito S, Takeda G: CDNA cloning of regeneration-specific genes in rice by differential screening of randomly amplified CDNAs using RAPD primers. Plant Cell Physiol 1994, 35(7):1003-1009.

11. Yu K, Pauls KP: Optimization of the PCR program for RAPD analysis. Nucleic Acids Res 1992, 20(10):2606.

12. Wen JS, Zhao WZ, Liu JW, Zhou H, Tao JP, Yan HJ, Liang Y, Zhou JJ, Jiang LF: Genomic analysis of a Chinese isolate of Getah-like virus and its phylogenetic relationship with other Alphaviruses. Virus Genes 2007, 35(3):597-603.

13. George J, Raju R: Alphavirus RNA genome repair and evolution: molecular characterization of infectious sindbis virus isolates lacking a known conserved motif at the 3 ' end of the genome. J Virol 2000, 74(20):9776-9785.

14. Hardy RW, Rice CM: Requirements at the 3' end of the sindbis virus genome for efficient synthesis of minus-strand RNA. J Virol 2005, 79(8):4630-4639.

15. Kuhn RJ, Griffin DE, Zhang H, Niesters HG, Strauss JH: Attenuation of Sindbis virus neurovirulence by using defined mutations in nontranslated regions of the genome RNA. J Virol 1992, 66(12):7121-7127.

16. Kuhn RJ, Hong Z, Strauss JH: Mutagenesis of the 3' nontranslated region of Sindbis virus RNA. J Virol 1990, 64(4):1465-1476.

17. Raju R, Hajjou M, Hill KR, Botta V, Botta S: In vivo addition of poly(A) tail and $\mathrm{AU}$-rich sequences to the 3 ' terminus of the Sindbis virus RNA genome: a novel 3'-end repair pathway. J Virol 1999, 73(3):2410-2419.

18. Zhai YG, Wang HY, Sun XH, Fu SH, Wang HQ, Attoui H, Tang Q, Liang GD: Complete sequence characterization of isolates of Getah virus (genus Alphavirus, family Togaviridae) from China. J Gen Virol 2008, 89(Pt 6):1446-1456.

19. Zhao W, Zhou G, He H: Cloning and primary analysis of 3 'end genome of two alphaviruses isolated from Hainan Province of China. Zhonghua Shi Yan He Lin Chuang Bing Du Xue Za Zhi 2000, 14(3):213-217.

20. Bryant JE, Crabtree MB, Nam VS, Yen NT, Duc HM, Miller BR: Isolation of arboviruses from mosquitoes collected in northern Vietnam. Am J Trop Med Hyg 2005, 73(2):470-473.

21. Chang $C Y$, Huang $C C$, Huang TS, Deng MC, Jong MH, Wang Fl: Isolation and characterization of a Sagiyama virus from domestic pigs. J Vet Diagn Invest 2006, 18(2):156-161.

22. Norder H, Lundstrom JO, Kozuch O, Magnius LO: Genetic relatedness of Sindbis virus strains from Europe, Middle East, and Africa. Virology 1996, 222(2):440-445.

23. Turell MJ, O'Guinn ML, Wasieloski LP Jr, Dohm DJ, Lee WJ, Cho HW, Kim HC, Burkett DA, Mores CN, Coleman RE, et al: Isolation of Japanese encephalitis and Getah viruses from mosquitoes (Diptera: Culicidae) collected near Camp Greaves, Gyonggi Province, Republic of Korea, 2000. J Med Entomol 2003, 40(4):580-584

24. Wang HQ, Liu WB, Yang DR, Liang Y, Wang JW, Zhang LS, Liu JW, Tao SJ, Lv XJ, Liang GD: Isolation and identification of arboviruses in Hebei Province. Zhonghua Shi Yan He Lin Chuang Bing Du Xue Za Zhi 2006, 20(1):52-55.

25. Hill MN, Varma MG, Mahadevan S, Meers PD: Arbovirus infections in Sarawak: observations on mosquitoes in the premonsoon period, September to December 1966. J Med Entomol 1969, 6(4):398-406.

26. Faragher SG, Dalgarno L: Regions of conservation and divergence in the 3' untranslated sequences of genomic RNA from Ross River virus isolates. J Mol Biol 1986, 190(2):141-148.

27. Wallner G, Mandl CW, Kunz C, Heinz FX: The flavivirus 3'-noncoding region: extensive size heterogeneity independent of evolutionary relationships among strains of tick-borne encephalitis virus. Virology 1995, 213(1):169-178.

28. Boom R, Sol CJ, Salimans MM, Jansen CL, Wertheim-van Dillen PM, van der Noordaa J: Rapid and simple method for purification of nucleic acids. J Clin Microbiol 1990, 28(3):495-503.

29. Zhai YG, Wang HQ, Fu SH, Liang GD: Molecular analysis on the capsid gene and 3' untranslation region of three Getah viruses isolated in China. Bing Du Xue Bao 2007, 23(4):270-275.

doi:10.1186/1471-2180-12-305

Cite this article as: Hu et al.: Identification of a novel Getah virus by Virus-Discovery-cDNA random amplified polymorphic DNA (RAPD). BMC Microbiology 2012 12:305.

\section{Submit your next manuscript to BioMed Central and take full advantage of:}

- Convenient online submission

- Thorough peer review

- No space constraints or color figure charges

- Immediate publication on acceptance

- Inclusion in PubMed, CAS, Scopus and Google Scholar

- Research which is freely available for redistribution 